\title{
Ventral Tegmental Area Glutamate Neurons: Electrophysiological Properties and Projections
}

\author{
Thomas S. Hnasko, ${ }^{1,2,3,4}$ Gregory 0. Hjelmstad, ${ }^{2,3}$ Howard L. Fields, ${ }^{2,3}$ and Robert H. Edwards ${ }^{1,2}$ \\ Departments of ${ }^{1}$ Physiology and ${ }^{2}$ Neurology, University of California San Francisco, San Francisco, California 94143, ${ }^{3}$ Ernest Gallo Clinic and Research \\ Center, Emeryville, California 94608, and ${ }^{4}$ Department of Neurosciences, University of California San Diego, La Jolla, California 92093
}

The ventral tegmental area (VTA) has a central role in the neural processes that underlie motivation and behavioral reinforcement. Although thought to contain only dopamine and GABA neurons, the VTA also includes a recently discovered population of glutamate neurons identified through the expression of the vesicular glutamate transporter VGLUT2. A subset of VGLUT2 ${ }^{+}$VTA neurons corelease dopamine with glutamate at terminals in the NAc, but others do not express dopaminergic markers and remain poorly characterized. Using transgenic mice that express fluorescent proteins in distinct cell populations, we now find that both dopamine and glutamate neurons in the medial VTA exhibit a smaller hyperpolarization-activated current $\left(I_{\mathrm{h}}\right)$ than more lateral dopamine neurons and less consistent inhibition by dopamine $\mathrm{D}_{2}$ receptor agonists. In addition, VGLUT2 ${ }^{+}$VTA neurons project to the nucleus accumbens (NAc), lateral habenula, ventral pallidum (VP), and amygdala. Optical stimulation of VGLUT2 ${ }^{+}$projections expressing channelrhodopsin-2 further reveals functional excitatory synapses in the VP as well as the NAc. Thus, glutamate neurons form a physiologically and anatomically distinct subpopulation of VTA projection neurons.

\section{Introduction}

Dopamine neurons of the ventral midbrain are classically divided into two populations: the nigrostriatal projection from substantia nigra pars compacta ( $\mathrm{SNc}$ ) to dorsal aspects of the striatum; and the mesolimbic projection from ventral tegmental area (VTA) to ventral striatum and other limbic regions. Dopamine neurons comprise $\sim 90 \%$ of the cells in the SNc, and their degeneration accounts for the loss of motor control in Parkinson's disease (Hornykiewicz, 1962). In addition to expressing the proteins required for catecholamine synthesis and release, SNc dopamine neurons exhibit distinctive electrophysiological properties, including a pronounced hyperpolarization-activated current $\left(I_{\mathrm{h}}\right)$ and inhibition by $\mathrm{D}_{2}$ dopamine receptor activation (Lacey et al., 1989).

Medial to the SNc, VTA dopamine neurons play an important role in motivation and reinforcement. In contrast to SNc dopamine neurons, they project to the ventral striatum, including the nucleus accumbens (NAc) core, shell, and olfactory tubercle, as

Received July 2, 2012; revised Aug. 28, 2012; accepted Sept. 4, 2012.

Author contributions: T.S.H., G.O.H., H.L.F., and R.H.E. designed research; T.S.H. and G.O.H. performed research; T.S.H. and G.O.H. analyzed data; T.S.H., G.O.H., H.L.F., and R.H.E. wrote the paper.

This work was supported by NIH Grants K01 DA026504 (to T.S.H.), R01 DA029776 (to G.0.H.), P01 DA10154 (R.H.E.), and R01 MH50712 (to R.H.E.) and by the State of California for medical research on alcohol and substance abuse through University of California San Francisco (UCSF). We thank Elyssa Margolis for advice and assistance initiating the experiments, Ole Kiehn and Lotta Borgius for generously providing VGLUT2-Cre transgenic mice, Karl Deisseroth for the AAV-DI0 plasmid, Chichen Qiu for technical assistance, and the UCSF Nikon Imaging Center for access to microscopes.

The authors declare no competing financial interests.

Correspondence should be addressed to either of the following: Thomas Hnasko, Department of Neurosciences, University of California San Diego, La Jolla, CA 92093, E-mail: thnasko@ucsd.edu; or Robert Edwards, Department of Physiology, University of California San Francisco, San Francisco, CA 94143, E-mail: robert.edwards@ucsf.edu.

DOI:10.1523/JNEUROSCI.3128-12.2012

Copyright $\odot 2012$ the authors $\quad 0270-6474 / 12 / 3215076-10 \$ 15.00 / 0$ well as to the amygdala, septum, hippocampus, and prefrontal cortex (PFC) (Fields et al., 2007; Ikemoto, 2007). Similar to dopamine neurons of the SNc, many VTA dopamine neurons express $I_{\mathrm{h}}$ and respond to $\mathrm{D}_{2}$ agonists. However, these properties are not unique to VTA dopamine neurons (Margolis et al., 2006, 2008; Lammel et al., 2008), which comprise only 55\% of cells in the rat VTA (Swanson, 1982; Margolis et al., 2006; Nair-Roberts et al., 2008).

In addition to dopamine neurons, the VTA contains a significant proportion of GABAergic neurons, which project to the PFC, NAc, and other regions (Fields et al., 2007). VTA GABAergic neurons also form local contacts onto both dopamine and nondopamine VTA neurons (Johnson and North, 1992a; Omelchenko and Sesack, 2009). In addition, a subset of VTA dopamine neurons expresses the vesicular glutamate transporter VGLUT2 (Kawano et al., 2006; Mendez et al., 2008; El Mestikawy et al., 2011; Yamaguchi et al., 2011), indicating the potential to corelease glutamate. Indeed, activation of VTA dopamine neurons elicits glutamatergic excitatory postsynaptic currents, EPSCs, in medium spiny neurons of the NAc (Chuhma et al., 2004; Hnasko et al., 2010; Stuber et al., 2010; Tecuapetla et al., 2010), demonstrating that a subset of dopamine-containing neurons can release physiologically significant amounts of glutamate.

However, it is important to note that most VGLUT2expressing neurons in the medial VTA are in fact not dopaminergic (Kawano et al., 2006; Yamaguchi et al., 2007, 2011). Axonal tracing studies have demonstrated that VGLUT2 ${ }^{+}$noncatecholamine neurons comprise a significant part of the total VTA projection to both NAc and PFC in rat (Yamaguchi et al., 2011; Gorelova et al., 2012). Since the exclusive localization of VGLUT2 to axon terminals makes it difficult to identify their cell bodies of origin (Fremeau et al., 2004; Takamori, 2006), these 
studies have relied on colocalization of a retrograde tracer with VGLUT2 mRNA (Yamaguchi et al., 2011) or an anterograde tracer with the punctate pattern of VGLUT2 immunoreactivity found in presynaptic fibers (Gorelova et al., 2012). However, these methods may lack the sensitivity to detect all projections and do not readily allow for the selective analysis of VGLUT2 ${ }^{+}$ neurons in living tissue. Taking advantage of bacterial artificial chromosome (BAC) transgenic mouse lines, we now provide the first electrophysiological characterization of VGLUT2 ${ }^{+}$nondopamine VTA neurons and demonstrate that these cells make anatomical and functional excitatory projections to regions overlapping with, but distinct from, their dopaminergic neighbors.

\section{Materials and Methods}

Experimental subjects. Acute slices through the ventral tegmental area, VTA, were made from 3- to 6-week old mice carrying the following three mutations: (1) one copy of a BAC transgene expressing enhanced green fluorescent protein (GFP) under the control of Slc17a6 (VGLUT2) regulatory elements [obtained from GENSAT (Gene Expression Nervous System Atlas) through MMRRC (Mutant Mouse Regional Resource Center) no. 011835-UCD] (Gong et al., 2003); (2) one copy of Cre recombinase expressed under the control of Slc6a3 [dopamine transporter (DAT)] regulatory elements (obtained from Jackson ImmunoResearch Laboratories, catalog no. 006660) (Bäckman et al., 2006); and (3) one copy of the CAG-tdTomato reporter targeted to the ROSA26 locus (obtained from Jackson ImmunoResearch Laboratories, catalog no. 007914) (Madisen et al., 2010). Mice were group housed in a colony maintained under a $12 \mathrm{~h}$ light/dark cycle with food and water available ad libitum. Both male and female mice were used, and all experiments were conducted in accordance with the University of California San Francisco Institutional Animal Care and Use Committee.

For anatomical tracing and acute slice recordings from neurons in the NAc or ventral pallidum (VP), adult ( $>8$ week) BAC transgenic mice expressing Cre recombinase under the control of Slc17a6 (VGLUT2) regulatory elements (Borgius et al., 2010) were injected with a conditional adeno-associated virus (AAV-EF1 $\alpha$-DIO-ChR2-mCherry) engineered to express ChR2-mCherry after Cre-mediated recombination (Tsai et al., 2009). Unilateral stereotaxic injections of $400 \mathrm{nl}\left(2 \times 10^{12}\right.$ genomes/ml) were infused at $100 \mathrm{nl} / \mathrm{min}$ using a Hamilton syringe into the medial VTA ( $x=-0.3, y=-3.4, z=-4.5$ relative to bregma) of mice anesthetized with ketamine (Fort Dodge) and xylazine (Phoenix Pharmaceutical). Note that for the anatomical tracing experiments, virus was diluted up to tenfold to limit spread outside the VTA. The animals were allowed to recover for at least 3 weeks before proceeding with the electrophysiological or anatomical experiments.

Histology. Mice were deeply anesthetized with pentobarbital (Lundbeck) perfused with ice-cold saline followed by $4 \%$ paraformaldehyde (PFA) in saline ( $\mathrm{pH} 7.2$ ), and the brains were removed, postfixed overnight in PFA, cryoprotected in 30\% sucrose, and frozen in super-chilled isopentane. Using a cryostat, $30-40 \mu \mathrm{m}$ sections were cut and stored in PBS containing $0.01 \%$ sodium azide at $4^{\circ} \mathrm{C}$ until stained. For immunohistochemistry, sections were washed three times with PBS containing $0.2 \%$ Triton X-100 (PBS-Tx), blocked for $1 \mathrm{~h}$ in PBS-Tx containing 4\% normal donkey serum, incubated overnight at $4^{\circ} \mathrm{C}$ in primary antibody with gentle agitation, washed three times in blocking solution, transferred to a secondary antibody for $>2 \mathrm{~h}$ at $4^{\circ} \mathrm{C}$ with gentle agitation, rinsed three times with PBS, mounted on to slides, and coverslipped with Fluormount-G (Southern Biotech). In some experiments, a $10 \mathrm{~min}$ incubation in DAPI was included after incubation in secondary antibody. Primary antibodies included rabbit-anti-tyrosine hydroxylase $(\mathrm{TH})$ (Millipore), sheep anti-TH (Pel-Freez Biologicals), chicken-anti-GFP (Invitrogen), and rabbit anti-DsRed (Clontech), all at 1:1000-2000 dilutions in blocking solution. Secondary antibodies of the appropriate species (Jackson ImmunoResearch) conjugated to Cy2, Cy3, or Cy5 were diluted 1:400-1000 in blocking solution. Images were collected using a Nikon Eclipse Ti-E motorized inverted epifluorescence microscope and a
Photometrics CoolSNAP HQ2 camera or a Nikon FN1 upright C1si spectral confocal microscope and Nikon Elements software. The same software was used to measure soma sizes of medial VTA dopamine and glutamate neurons in the interfascicular nucleus, the rostral linear nucleus, and caudal linear nucleus regions. For fiber colocalization analysis, fibers were identified from at least two confocal images per brain region, mCherry ${ }^{+}$fibers were identified, and the fraction colocalizing for $\mathrm{TH}$ was reported.

Electrophysiology. Mice were given a lethal dose of Euthasol (Virbac Animal Health) and transcardially perfused with $10 \mathrm{ml}$ ice-cold sucroseACSF (in mu: 75 sucrose, $87 \mathrm{NaCl}, 2.5 \mathrm{KCl}, 7 \mathrm{MgCl}_{2}, 0.5 \mathrm{CaCl}_{2}, 25$ $\mathrm{NaHCO}_{3}, 1.25 \mathrm{NaH}_{2} \mathrm{PO}_{4}$ ) saturated with $95 \% \mathrm{O}_{2}$ and $5 \% \mathrm{CO}_{2}$. Brains were removed into ice-cold sucrose-ACSF and, horizontal sections through the VTA or coronal sections through the NAc and VP were cut at $150 \mu \mathrm{m}$ using a vibratome (VT1200, Leica). Slices were incubated at $31^{\circ} \mathrm{C}$ for $>30 \mathrm{~min}$ in a holding chamber containing ACSF (in mM: $126 \mathrm{NaCl}$, $2.5 \mathrm{KCl}, 1.2 \mathrm{MgCl}_{2}, 2.4 \mathrm{CaCl}_{2}, 25 \mathrm{NaHCO}_{3}, 1.4 \mathrm{NaH}_{2} \mathrm{PO}_{4}, 11$ glucose) saturated with $95 \% \mathrm{O}_{2}$ and $5 \% \mathrm{CO}_{2}$. While recording, slices were superfused with $31^{\circ} \mathrm{C}$ ACSF at $2 \mathrm{ml} / \mathrm{min}$.

Whole-cell patch-clamp recordings from $\mathrm{RFP}^{+}$dopamine or $\mathrm{GFP}^{+}$ glutamate VTA neurons were performed under visual guidance using a differential interference contrast upright microscope (Olympus) with infrared illumination, $2.5-5 \mathrm{M} \Omega$ resistance pipettes filled with internal solution (in mM: 120 potassium gluconate, $2.5 \mathrm{KCl}, 10$ HEPES, 0.2 EGTA, $8 \mathrm{NaCl}, 2 \mathrm{Mg}$-ATP, and $0.3 \mathrm{Mg}-\mathrm{GTP}, \mathrm{pH}$ 7.2) and either an Axopatch $1 \mathrm{D}$ or $200 \mathrm{~B}$ amplifier (Molecular Devices) with a $2 \mathrm{kHz}$ lowpass Bessel filter, a NIDAQ board interface with $5 \mathrm{kHz}$ digitization (National Instruments), and custom-made acquisition software using IGOR Pro (WaveMetrics). The $I_{\mathrm{h}}$ was measured in voltage-clamp mode, holding cells at $-60 \mathrm{mV}$ and stepping to $-40,-50,-70,-80,-90,-100$, -110 , and $-120 \mathrm{mV} . I_{\mathrm{h}}$ amplitude was defined as the initial current following the $-120 \mathrm{mV}$ step subtracted from the current at the end of the $750 \mathrm{~ms}$ step. Cells were defined as $I_{\mathrm{h}}{ }^{+}$if they exhibited a negative slope during the -60 to $-120 \mathrm{mV}$ step.

Measurement of membrane potential, action potential (AP) firing rate and waveform were made in current clamp $(I=0)$. Input resistance was monitored with a $4 \mathrm{mV}$ hyperpolarizing voltage step every $10 \mathrm{~s}$ sweep. The liquid junction potential was calculated at $-14 \mathrm{mV}$ and corrected for in Table 1 and Figure 3. Initial membrane potential $\left(V_{m}\right)$ was recorded upon entering current-clamp mode immediately after break-in. The spontaneous firing rate was calculated as the average over the first $30 \mathrm{~s}$ following break in. AP threshold was defined by the $V_{m}$ when the first derivative of $\mathrm{V}_{\mathrm{m}}$ exceeded $5 \mathrm{~V} / \mathrm{s}$. AP width was the time between the AP threshold and when $\mathrm{V}_{\mathrm{m}}$ re-crossed the threshold. Quinpirole (Sigma) was bath applied at a final concentration of $1 \mu \mathrm{M}$ and within cell statistics (two-tailed paired $t$ test) were used to define a cell as responsive to quinpirole application; cells with a firing rate or $\mathrm{V}_{\mathrm{m}}$ stable for $>5 \mathrm{~min}$ were sampled for $4 \mathrm{~min}$ (eight consecutive $30 \mathrm{~s}$ bins), before and $5 \mathrm{~min}$ after drug application.

Whole-cell voltage-clamp recordings of medium spiny neurons in NAc $\left(V_{h}=-70\right)$ or VP neurons $\left(V_{h}=-60\right)$ were performed on coronal brain slices prepared as above using a cesium-based internal solution (in mm: 125 cesium methanesulfonate, $3 \mathrm{NaCl}, 20 \mathrm{HEPES}, \mathrm{pH}$ 7.3, 0.4 EGTA, 4 Mg-ATP, $0.4 \mathrm{Mg}$-GTP, and 5 tetraethylammonium to block $\mathrm{K}^{+}$channels). Series resistance was monitored by measuring the peak of the capacitive transient to a $4 \mathrm{mV}$ hyperpolarizing voltage step applied to each sweep. Photocurrents were induced by optical illumination $(0.1 \mathrm{~Hz}, 6-60 \mathrm{~mW})$ through the objective with two $2-5$ $\mathrm{ms}$ blue light pulses separated by $50 \mathrm{~ms}$ and delivered by an LED through the objective light path. Six to twelve sweeps were averaged offline, and peak amplitude was measured to assess light-evoked current size. AMPAR-mediated currents were blocked using 6,7-dinitroquinoxaline-2,3dione (DNQX; Tocris Bioscience) bath applied to a final concentration of $10 \mu \mathrm{M}$. GABA receptor-mediated currents were blocked with bath application of either $100 \mu \mathrm{M}$ picrotoxin (Tocris Bioscience) or 10 $\mu \mathrm{M}$ gabazine (Sigma). 


\section{Results}

Visualization of VGLUT2 ${ }^{+}$glutamate neurons in the VTA using transgenic reporter mice

To identify VTA glutamate neurons ex vivo, we used BAC transgenic mouse lines that express either GFP (Gong et al., 2003; Hnasko et al., 2010) or Cre recombinase (Borgius et al., 2010) under the control of VGLUT2 (Slc17a6) regulatory elements (Fig. 1A1). To identify dopamine neurons as well, the VGLUT2-GFP mice were crossed onto another line that expresses Cre recombinase under the control of the Slc6a3 gene (the dopamine transporter, DAT) (Bäckman et al., 2006) and contains the red fluorescent protein (RFP) floxedstop reporter tdTomato targeted to the Rosa26 locus (Madisen et al., 2010) (Fig.1A1,A2). Mice carrying these three genetic modifications enabled us to visualize both $\mathrm{GFP}^{+}$glutamate neurons and $\mathrm{RFP}^{+}$dopamine neurons within the same brain slices. It is important to acknowledge, however, that the very strong expression of RFP reporter in dopamine neurons and the broad emission spectrum of tdTomato allowed us to identify $\mathrm{GFP}^{+}$/ $\mathrm{RFP}^{-}$neurons as "glutamate only," but made it difficult to exclude the expression of GFP (and hence VGLUT2) by RFP ${ }^{+}$ dopamine neurons. As a result, we have compared glutamate-only VTA neurons with dopamine neurons, some of which express VGLUT2 and corelease glutamate (Chuhma et al., 2004; Hnasko et al., 2010; Stuber et al., 2010; Tecuapetla et al., 2010; El Mestikawy et al., 2011).

In horizontal brain slices through the VTA, GFP ${ }^{+}$glutamate neurons were interspersed with $\mathrm{RFP}^{+}$dopamine neurons but concentrated near midline structures including the rostral linear nucleus (RLi), interfascicular nucleus (IF), and caudal linear nucleus (CLi) (Fig. 1), consistent with previous anatomical studies of VGLUT2 mRNA expression in rat (Kawano et al., 2006; Yamaguchi et al., 2011). Morphologically, $\mathrm{GFP}^{+}$glutamate neurons tended to be smaller than $\mathrm{RFP}^{+}$dopamine neurons in the medial VTA (glutamate, $n=166$, mean \pm SEM $=74.1 \pm 3.1 \mu^{2}$; dopamine, $n=400$, mean \pm SEM $=127.9 \pm 3.7 \mu^{2} ; p<0.001$ by two-tailed $t$ test). Although immunostaining detected $\mathrm{GFP}^{+}$neurons through more lateral regions of the VTA (i.e., paranigral nucleus and parabrachial pigmented area) (Fig. 1A) (Hnasko et al., 2010), these cells were rarely observed in acute, live slice preparations. Presumably due to relatively weak transgene expression from the endogenous promoter, the VGLUT2-GFP line appears to underreport the total number of VTA glutamate neurons based both on previously published work (Kawano et al., 2006; Yamaguchi et al., 2011) and our own experiments with the transgenic VGLUT2-Cre line (for description, see below: VTA glutamate neurons project to
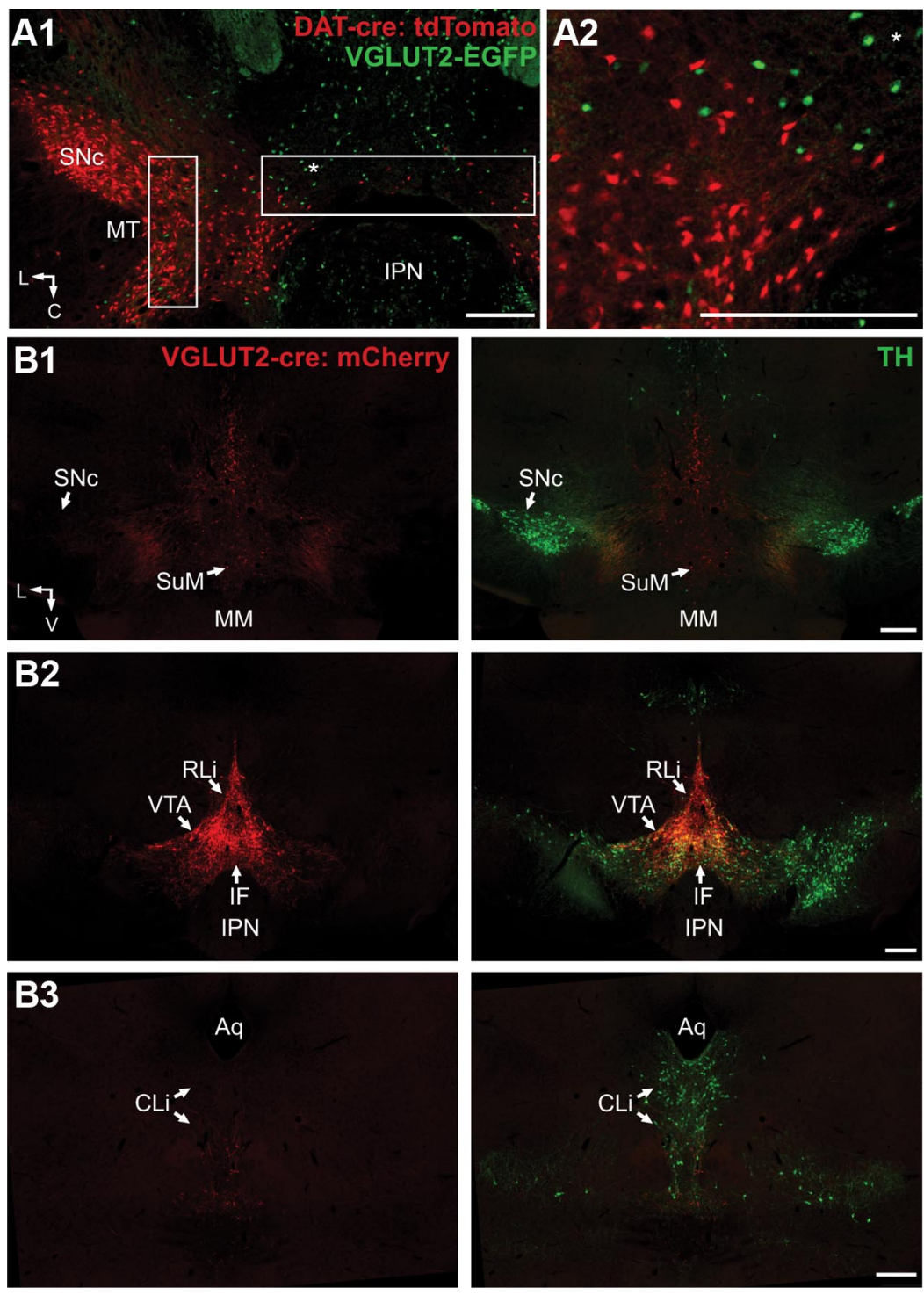

Figure 1. Identification of VTA glutamate neurons. A1, Horizontal section through the VTA of a mouse expressing GFP under the control of VGLUT2 regulatory elements (VGLUT2-GFP), Cre recombinase under the control of DAT regulatory elements (DAT-Cre), and the Rosa26 flox-stop tdTomato reporter to identify glutamate and catecholamine neurons, respectively. For whole-cell recordings, GFP ${ }^{+}$glutamate and tdTomato ${ }^{+}$dopamine neurons were defined as medial (within the horizontal box rostral to the interpeduncular nucleus, IPN), or lateral (within the vertical box near MT, the medial terminal nucleus of the accessory optic tract). A2, Magnified image of medial VTA (reference asterisk $\left(^{*}\right)$ marks the same location in $\mathbf{A} \mathbf{1}$ and $\mathbf{A 2}$ ). B1, B2, B3, Conditional viral vector AAV-EF1 $\alpha$-DI0-ChR2-mCherry was injected into the VTA of VGLUT2-Cre mice, and $>3$ weeks later coronal sections from rostral (bregma, $-2.9 \mathrm{~mm})(\boldsymbol{B} 1)$, central (bregma, $-3.7 \mathrm{~mm})(\boldsymbol{B} 2$ ), and caudal (bregma, $-4.3 \mathrm{~mm})(\boldsymbol{B} 3)$ midbrain were stained for mCherry (red) and TH (green). In this mouse, virus spread (indicated by mCherry expression) was limited to the VTA and supramammillary nucleus (SuM). Scale bars, $250 \mu \mathrm{m}$; MM, mammillary nucleus; IF, interfascicular nucleus; RLi, rostral linear nucleus; CLi, caudal linear nucleus; Aq, aqueduct; C, caudal; L, lateral; V, ventral.

ventral striatum, PFC, amygdala, ventral pallidum, and lateral habenula) (Fig. $1 B$ ). Our conclusions may therefore be biased toward those VTA glutamate neurons that express higher levels of the GFP transgene, presumably reflecting higher levels of VGLUT2.

\section{Medial glutamate, medial dopamine, and lateral dopamine} VTA neurons differ in their membrane properties

To compare VTA glutamate neurons with their dopaminereleasing neighbors, we focused our electrophysiological analysis on glutamate and dopamine neurons in the medial VTA. Since previous work on VTA neurons has generally addressed more lateral portions of the VTA near the medial terminal nucleus of 

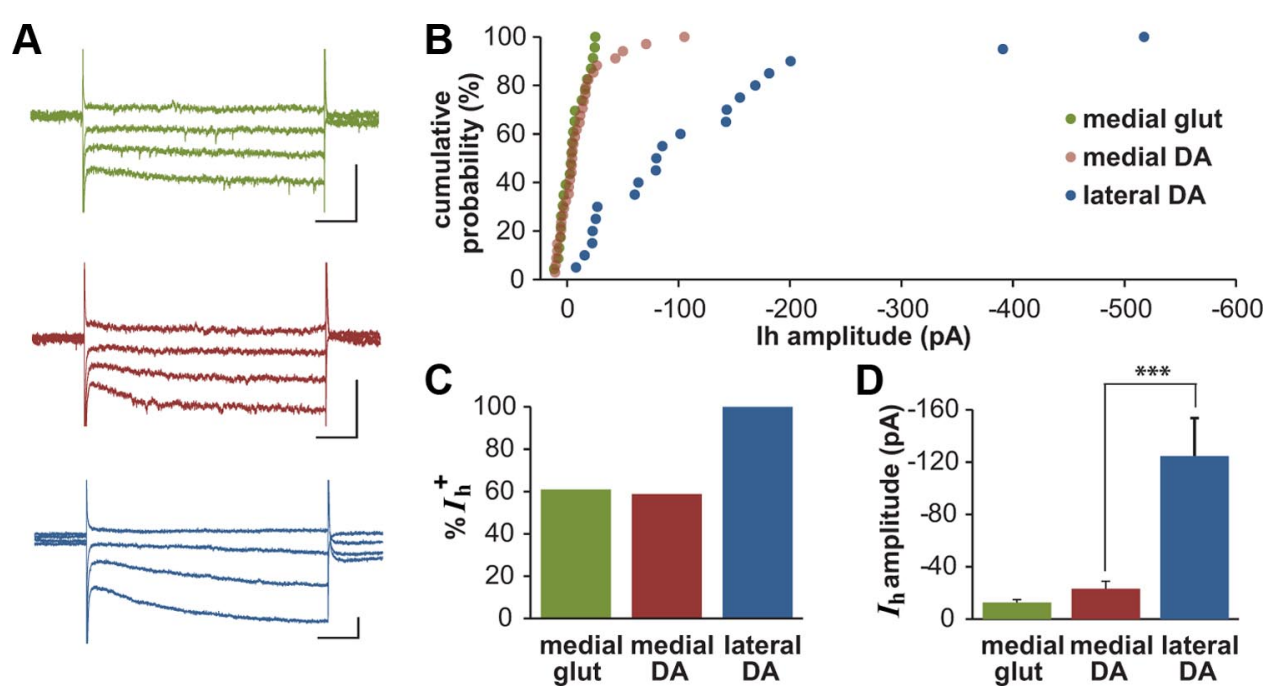

Figure 2. Medial dopamine and glutamate neurons express less hyperpolarization-activated current, $I_{\mathrm{h}}$, than lateral VTA dopamine neurons. $\boldsymbol{A}$, Representative traces of $I_{\mathrm{h}}{ }^{+}$medial glutamate (green), medial dopamine (red), and lateral dopamine (blue) neurons in the VTA. Recording in voltage clamp, the cells were held at $-60 \mathrm{mV}$ and jumped sequentially to $-50,-80,-100$, and $-120 \mathrm{mV}$. Scale bars, $100 \mathrm{pA}$ and $100 \mathrm{~ms}$. B, Cumulative frequency distribution of $I_{\mathrm{h}}$ amplitudes after a -60 to $-120 \mathrm{mV}$ step shows much larger $I_{\mathrm{h}}$ in lateral VTA dopamine neurons. $\boldsymbol{C}$, The lateral VTA contains a larger fraction of cells that express detectable $I_{\mathrm{h}} . D$, Average $I_{\mathrm{h}}$ amplitude of $I_{\mathrm{h}}{ }^{+}$cells. Data were analyzed by one-way ANOVA across groups (main effect of group; $F_{(2,51)}=11.0, p<$ 0.001 ) followed by Tukey's post hoc test (* $p<0.001) ; n=14$ (medial glut), 20 (medial DA), 20 (lateral DA).

Table 1. Basic membrane properties and action potential characteristics of neurons in the VTA

\begin{tabular}{|c|c|c|c|c|c|c|c|}
\hline & $V_{m}(m v)$ & Firing rate $(\mathrm{Hz})$ & AP threshold (mV) & AP duration (ms) & AHP peak (mV) & AHP time to peak (ms) & AHP at $50 \mathrm{~ms}(\mathrm{mV})$ \\
\hline Medial glut & $-59.6 \pm 1.6^{*}$ & $3.7 \pm 0.8$ & $-41.3 \pm 0.9^{*}$ & $2.6 \pm 0.2^{*}$ & $-68.6 \pm 2.0^{*}$ & $15.4 \pm 3.2$ & $-62.2 \pm 1.2$ \\
\hline Medial DA & $-54.7 \pm 1.3$ & $2.9 \pm 0.4$ & $-38.1 \pm 0.9$ & $3.3 \pm 0.2$ & $-62.5 \pm 1.7$ & $19.0 \pm 2.2$ & $-58.6 \pm 1.6$ \\
\hline Lateral DA & $-56.8 \pm 0.9$ & $1.1 \pm 0.3^{* *}$ & $-41.7 \pm 1.0^{*}$ & $2.8 \pm 0.1$ & $-73.1 \pm 1.8^{* * *}$ & $28.2 \pm 5.2$ & $-71.7 \pm 1.9^{* * *}$ \\
\hline
\end{tabular}

Statistically significant difference relative to medial dopamine neurons, two-tailed $t$ test, ${ }^{*} p<0.05,{ }^{* *} p<0.01,{ }^{* * *} p<0.001 . \mathrm{V}_{\mathrm{m}}$, initial membrane potential; AP, action potential; AHP, afterhyperpolarization.

the accessory optic tract (MT), we also compared medial and lateral VTA dopamine neurons (see boxes in Fig. 1A1).

Within the midbrain, $I_{\mathrm{h}}$ is expressed by dopamine neurons in both the SNc and VTA (Lacey et al., 1989; Margolis et al., 2006) (but see also Lammel et al., 2008). Hyperpolarization-activated cyclic nucleotide-gated channels mediate the $I_{\mathrm{h}}$ conductance, an important modulator of resting membrane potential and pacemaking in many neurons (Pape, 1996); in the VTA, $I_{\mathrm{h}}$ may contribute to the dendritic integration of synaptic inputs (Robinson and Siegelbaum, 2003). To determine whether glutamate-only neurons in the VTA express $I_{\mathrm{h}}$, we recorded from $\mathrm{GFP}^{+} / \mathrm{RFP}^{-}$medial VTA neurons using whole-cell voltage clamp. Roughly half of the glutamate only neurons exhibit detectable $I_{\mathrm{h}}$ (Fig. $2 A-C$ ), but these currents were generally quite small (Fig. $2 B, D$ ). $\mathrm{RFP}^{+}$medial dopamine neurons also generally exhibited a small or undetectable $I_{\mathrm{h}}$, with cumulative probability profiles very similar to their glutamatergic nondopamine neighbors (Fig. $2 B$ ). Thus, the expression of a small $I_{\mathrm{h}}(<25 \mathrm{pA})$ cannot be used to distinguish medial dopamine from glutamate only neurons, and the absence of $I_{\mathrm{h}}$ cannot be used to exclude a dopaminergic phenotype, at least in the medial VTA of the mouse (Lammel et al., 2008; Zhang et al., 2010). In contrast, $\mathrm{RFP}^{+}$dopamine neurons in the lateral VTA typically displayed a much larger $I_{\mathrm{h}}$ (Fig. 2A-D).

To assess basic membrane properties, we measured initial membrane potential, $\mathrm{V}_{\mathrm{m}}$, initial firing rate, and action potential (AP) waveforms in whole-cell current clamp. Relative to neighboring dopamine neurons, medial VTA glutamate neurons were only slightly more hyperpolarized at rest and exhibited only a slightly shorter AP duration (Table 1). However, medial dopamine neurons showed a substantially smaller afterhyperpolarization (AHP) following the AP than lateral dopamine neurons. Indeed, lateral VTA neurons typi- cally exhibited both a larger and more prolonged AHP than medial dopamine or glutamate only neurons (Table 1).

$\mathrm{D}_{2}$ dopamine receptors in the VTA are generally thought to function as autoreceptors, responding to somatodendritically released dopamine and thereby inhibiting the activity of dopamine neurons (Johnson and North, 1992b). However, $\mathrm{D}_{2}$ receptor activation has also been reported to inhibit many nondopamine VTA neurons (Cameron et al., 1997; Margolis et al., 2006; Luo et al., 2010). We therefore tested the sensitivity of VTA glutamate-only neurons to $\mathrm{D}_{2}$ receptor stimulation, using bath application of the $\mathrm{D}_{2}$ agonist quinpirole $(1 \mu \mathrm{M})$. Both medial glutamate only (Fig. $3 A$ ) and medial dopamine neurons (Fig. 3B) exhibited heterogeneous responses to quinpirole, with $42 \%$ (5/12 medial dopamine and $5 / 12$ glutamate neurons) showing inhibition by within-cell paired $t$ test, but others showed either no effect or even depolarization (medial dopamine neurons showed a mean change in $\mathrm{V}_{\mathrm{m}}$ of $0.1 \pm 1.2 \mathrm{mV}$; medial glutamate neurons, $0.3 \pm 2.4 \mathrm{mV})$. In contrast, quinpirole inhibited $70 \%$ of lateral dopamine neurons ( $p<0.05$ by two-tailed within-cell paired $t$ test); with a mean reduction in $\mathrm{V}_{\mathrm{m}}$ of $4.0 \pm 1.8 \mathrm{mV}\left(F_{(1,9)}=\right.$ $4.86, p=0.055$ by repeated-measures ANOVA) (Fig. $3 C$ ). Thus, both medial VTA glutamate only and dopamine neurons are less reliably inhibited by $\mathrm{D}_{2}$ receptor stimulation than more lateral dopamine neurons.

\section{VTA glutamate neurons project to ventral striatum, PFC,} amygdala, ventral pallidum, and lateral habenula

To identify the projection targets of VTA glutamate neurons, we took advantage of a conditional adeno-associated virus (AAV) expressing ChR2-mCherry (Fig. $1 B$ ). After activation by Cre recombinase, the ChR2-mCherry labels axons and terminals, in addition to cell bodies (Tsai et al., 2009), so that the injection of 

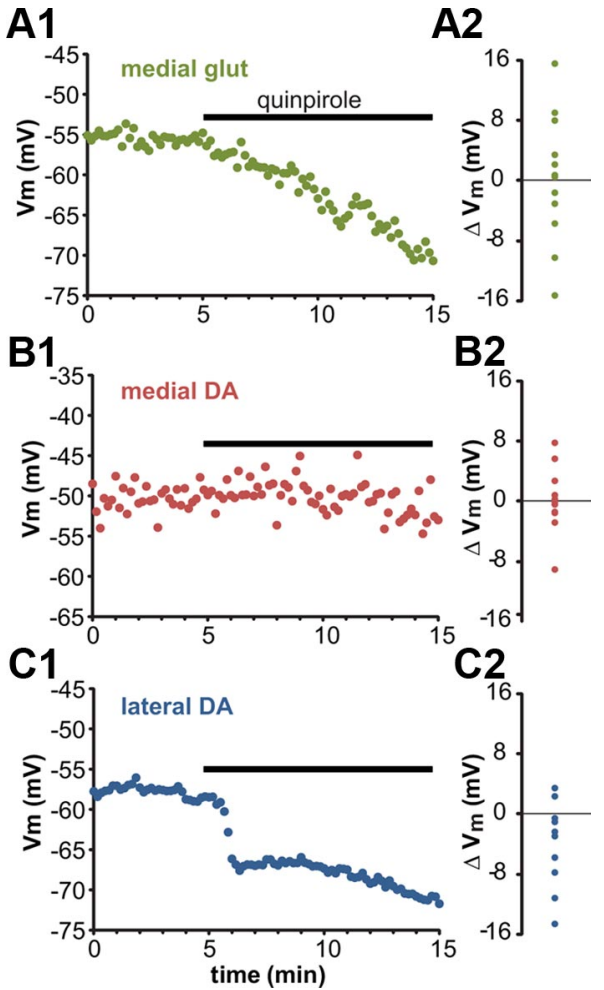

Figure 3. Response to $D_{2}$ dopamine receptor $\left(D_{2} R\right)$ activation differs among medial glutamate, medial dopamine, and lateral dopamine VTA neurons. $\mathbf{A 1}, \boldsymbol{A 2}$, A VTA glutamate neuron hyperpolarizes in response to quinpirole $(\boldsymbol{A} \mathbf{1})$, but a scatter plot distribution of responses shows that VTA glutamate neurons respond heterogeneously to D2R agonist application (A2). B1, B2, A medial VTA dopamine neuron does not respond to quinpirole $(\boldsymbol{B} 1)$, but the distribution shows similarly heterogeneous responsiveness to $D_{2}$ stimulation by medial VTA dopamine neurons (B2). C1, C2, Lateral VTA dopamine neurons hyperpolarize in response to quinpirole as shown by the example time course (C) and distribution of responses (C2). Several cells inhibited by quinpirole were firing at the time of drug application and so were not included in the scatter plot distributions of $\Delta V_{m}$.

this virus into VGLUT2-Cre mice should restrict expression of ChR2-mCherry to both glutamate only and dopamine neurons that corelease glutamate. Of 26 mice receiving VTA injections, we identified three with expression of mCherry tightly restricted to the medial cell groups of the VTA (i.e., parabrachial pigmented area, paranigral nucleus, interfascicular nucleus, rostral and caudal linear nuclei, and supramammilary nucleus) (Fig. $1 B$ ). Many other injected mice expressed reporter in the VTA, but also in neighboring nuclei (e.g., interpeduncular nucleus, red nucleus, and mammillary bodies) and were therefore not used to define the projections of VTA glutamate neurons.

We have previously demonstrated that glutamate corelease from dopamine neurons in the NAc depends on their expression of VGLUT2 (Hnasko et al., 2010; Stuber et al., 2010). We were therefore not surprised to find mCherry $^{+}$fibers in the NAc of injected VGLUT2-Cre mice (Fig. 4A, C,E). The dorsal striatum contained occasional mCherry $^{+}$fibers, but the ventral striatum, particularly the medial shell of the NAc, received more robust innervation. Confocal microscopy further demonstrated that a majority $(88 \%, n=240)$ of mCherry-expressing glutamate fibers in the medial shell of the NAc colocalized with the catecholamine biosynthetic enzyme tyrosine hydroxylase, $\mathrm{TH}$, supporting previous evidence that both $\mathrm{TH}^{+}$and $\mathrm{TH}^{-}$VTA glutamate neurons project to the NAc (Yamaguchi et al., 2011).

Consistent with previous electrophysiological and anatomical studies (Lavin et al., 2005; Gorelova et al., 2012), we observed both $\mathrm{TH}^{+}(73 \%, n=145)$ and $\mathrm{TH}^{-}$mCherry ${ }^{+}$glutamatergic fibers in the PFC (Fig. $4 A, B$ ), although both the dopaminergic and glutamatergic projection from midbrain appear much weaker in mice than in rat. In addition, Cherry $^{+}$fibers were observed in the amygdala (Fig. $5 C$ ). Thus, VTA glutamatergic neurons project to many of the same regions where dopamine is also released.

We also observed dense mCherry ${ }^{+}$fibers in two structures not known to receive strong dopaminergic input. First, many $\mathrm{mCherry}^{+}$fibers were observed innervating the rostrocaudal extent of the ventral pallidum, VP (Fig. 5A,B). In rostral coronal sections, these fibers innervate the "finger-like" extensions of the VP found ventral to the NAc and dorsal to the olfactory tubercle (Fig. 4A, $C, E$ ). Second, we observed dense innervation of the lateral habenula (LHb) (Fig. 5D). Greater than 98\% of mCherry ${ }^{+}$ fibers in these regions lacked TH staining; thus, VTA projections to the VP and LHb appear to release only glutamate. Although it remains possible that glutamate only neurons do in fact store and release dopamine but fail to express detectable levels of $\mathrm{TH}$, the results suggest that they nonetheless represent a novel population that has previously escaped observation.

\section{VTA glutamate neurons form excitatory synapses in the nucleus accumbens and ventral pallidum}

To determine whether VGLUT2 ${ }^{+}$projections from the VTA form functional excitatory synapses, we used light to stimulate terminals expressing ChR2-mCherry after stereotactic injection of the conditional AAV into the midbrain of VGLUT2-Cre mice. Since stereotactic injection of the same virus into DAT-Cre mice confers VGLUT2-dependent, light-evoked excitatory responses in the NAc (Stuber et al., 2010; Tecuapetla et al., 2010), we were not surprised to see light-evoked currents in the same region of VGLUT2-Cre mice (Fig. 6A). Indeed, optically evoked excitatory connections were observed in all cells surrounded by fibers robustly expressing mCherry and were not present in regions devoid of mCherry ${ }^{+}$fibers. The peak amplitude of light-evoked currents when held at $-70 \mathrm{mV}$ averaged $-39 \pm 15 \mathrm{pA}(n=12)$ and showed sensitivity to DNQX, indicating AMPAR-mediated currents (Fig. $6 B, C$ ). In addition, when held at $+40 \mathrm{mV}$, light evoked $N$-methyl-D-aspartate receptor (NMDAR)-mediated currents in medium spiny neurons of the medial shell of the NAc (Fig. 6A). Further, some neurons showed outward IPSCs in response to light stimulation when the neuron was held at $0 \mathrm{mV}$. These IPSCs were blocked by either the $\mathrm{Cl}^{-}$channel blocker picrotoxin or the $\mathrm{GABA}_{\mathrm{A}}$ receptor antagonist gabazine (data not shown) and had delayed onsets, consistent with the activation of polysynaptic circuits (Fig. $6 \mathrm{~A}$ ).

To characterize the novel projection from VTA to VP, we recorded the response of VP neurons to optical stimulation of the ChR2-mCherry terminals derived from VGLUT2 ${ }^{+}$VTA neurons. Again, we found both AMPAR- and NMDAR-mediated currents (Fig. $6 D$ ), with peak AMPAR currents averaging $41 \pm 10$ pA $(n=22)$ and sensitive to DNQX (Fig. 6E,F). VGLUT2expressing nondopamine neurons in the VTA thus form functional excitatory synapses in the VP. We also observed IPSCs in some VP neurons when holding the cell at $0 \mathrm{mV}$. As in the NAc, these currents were sensitive to picrotoxin and gabazine, although the synaptic delay was much shorter than that observed in the NAc, raising the possibility of GABA release by VGLUT2 ${ }^{+}$ neurons. 

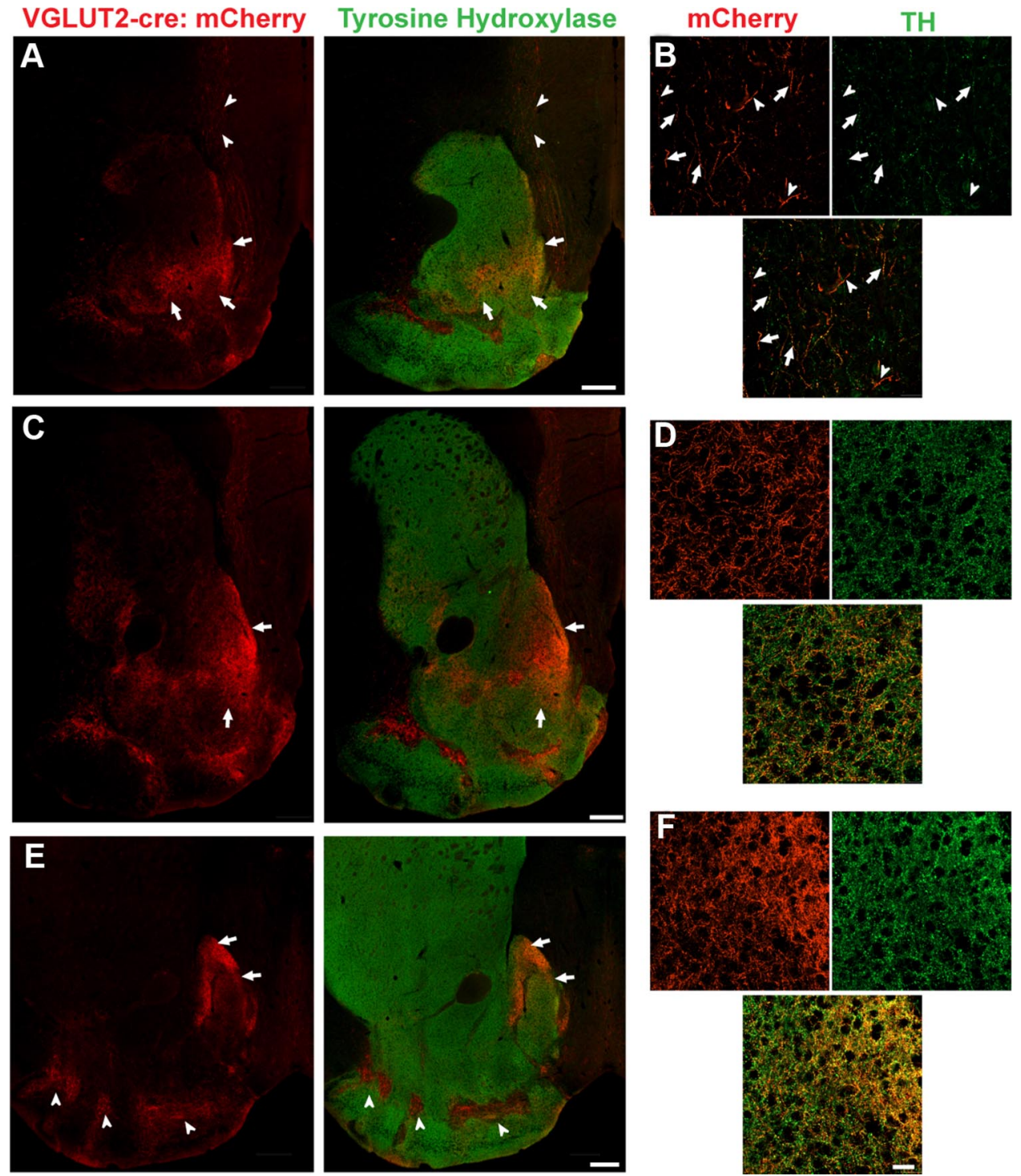

Figure 4. VTA glutamate neurons project to nucleus accumbens and prefrontal cortex. $A, B$, More than 3 weeks after stereotactic injection of AAV-EF1 $\alpha$-DI0-ChR2-mCherry into the medial VTA (Fig. 1B), a coronal section through the striatum ( $A$ ) shows strong labeling of glutamatergic projections (red) from the VTA to the medial and ventromedial shell of the nucleus accumbens (NAc) (arrows). Sparse labeling also occurs in the PFC (arrowheads). Sections were double stained for TH (green) to identify the projections from midbrain dopamine neurons. A confocal image of the PFC (B) shows $m$ Cherry ${ }^{+}$glutamate fibers that colocalize with TH (arrows) and others which do not (arrowheads). $\boldsymbol{C}, \boldsymbol{D}$, In a coronal section through the central $\operatorname{NAc}(\boldsymbol{C})$, dense $\mathrm{mCherry}{ }^{+}$glutamatergic fibers project throughout the shell of the NAc, in particular medially (arrows). A confocal image in the NAc shell (D) demonstrates widespread colocalization of mCherry ${ }^{+}$(glutamatergic) and dopaminergic fibers. $\boldsymbol{E}, \boldsymbol{F}$, A coronal section through the caudal $\operatorname{NAc}(\boldsymbol{E})$ shows mCherry ${ }^{+}$VTA glutamate projections concentrated in the dorsal cone of the medial shell (arrow) and $(\boldsymbol{F})$ colocalizing with TH by confocal microscopy. Glutamate fibers from the VTA are also observed in the rostral finger-like projections of the VP (arrowheads), and these label only sparsely for TH (see Fig. 5). Scale bars, $A, C, E, 250 \mu \mathrm{m} ; \boldsymbol{B}, \boldsymbol{D}, \boldsymbol{F}, 50 \mu \mathrm{m}$.

\section{Discussion}

In addition to dopamine neurons that corelease glutamate (Hnasko and Edwards, 2012), we find that the midbrain contains a distinct set of glutamatergic projection neurons that do not coexpress dopaminergic markers (Kawano et al., 2006; Yamaguchi et al., 2007, 2011). Here we present the first electrophysiological characterization of these glutamate-only neurons and find that they share features found in medial VTA dopamine neurons, which are themselves different from dopamine neurons in more lateral VTA. In addition to confirming previous work showing that VTA glutamate-only neurons project to known targets of dopamine neurons (Yamaguchi et al., 2011; Gorelova et al., 2012), we anatomically and functionally identify previously undescribed excitatory projections from the VTA to the VP and LHb.
Electrophysiological properties of VTA glutamate neurons The electrophysiological properties of VTA glutamate-only neurons show important differences from more lateral midbrain dopamine neurons. Dopamine neurons of the SNc show spontaneous pacemaking of $\sim 1-4 \mathrm{~Hz}$, robust hyperpolarizationactivated cyclic nucleotide-gated currents $\left(I_{\mathrm{h}}\right)$, and pharmacological inhibition by $\mathrm{D}_{2}$ dopamine autoreceptors (Lacey et al., 1989). VTA neurons exhibit many of the same properties; however, most work has targeted neurons of the lateral VTA that project to lateral parts of the ventral striatum, NAc core, and olfactory tubercle (Ikemoto, 2007). In addition, the VTA is considerably more heterogeneous than suspected, with GABA neurons varying in number along the rostrocaudal axis (Olson and Nestler, 2007) and glutamate neurons along both the mediolateral and rostrocaudal axes (Kawano et al., 2006; 
Yamaguchi et al., 2011). Further, recent work has shown that pacemaking, $I_{\mathrm{h}}$, and $\mathrm{D}_{2}$ receptor sensitivity are neither expressed by all dopamine neurons of the VTA nor restricted to dopamine neurons (Margolis et al., 2006, 2008; Lammel et al., 2008; Luo et al., 2008; Zhang et al., 2010). We have thus used transgenic mice expressing GFP in the glutamate neurons and RFP in dopamine neurons to identify and compare these cell populations.

Since glutamate neurons localize primarily to medial aspects of the VTA (i.e., IF, RLi, and CLi nuclei), we compared their properties to those of neighboring RFP-expressing dopamine neurons. In contrast to more lateral VTA dopamine populations, both glutamate-only and dopamine neurons of the medial VTA express little or no $I_{\mathrm{h}}$. Similarly, medial VTA neurons are less likely to be hyperpolarized by $\mathrm{D}_{2}$ receptor stimulation than their lateral counterparts. The smaller $I_{\mathrm{h}}$, shallower AHP, and reduced sensitivity to dopamine-mediated inhibition may indicate that medial VTA neurons are more excitable, and indeed they display a faster initial firing rate than those observed in the lateral VTA.

On the other hand, medial VTA dopamine neurons resemble their glutamateonly neighbors. In particular, medial glutamate-only and dopamine neurons both exhibit very small $I_{\mathrm{h}}$ and variable sensitivity to $D_{2}$ receptor agonists. They also show faster initial firing than more lateral dopamine neurons. Thus, dopamine and glutamate-only neurons of the medial VTA resemble each other more than they do lateral dopamine neurons, at least in terms of electrophysiological properties. As a result, properties such as $I_{\mathrm{h}}$ that have been relied on to identify neurons as dopaminergic cannot be used to distinguish dopamine from glutamate-only neurons in the medial VTA, and properties previously ascribed to dopamine neurons may in fact reflect the activity of glutamate neurons. Consistent with these findings, recent work examining the properties of VTA dopamine neurons based on projection target suggests that medial VTA dopamine neurons express less DAT, fire more rapidly, and exhibit less $\mathrm{D}_{2}$ receptor sensitivity than their lateral counterparts (Lammel et al., 2008), features that correlate with an increased AMPA/NMDA ratio in response to behaviorally relevant aversive stimuli (Lammel et al., 2011). Considering their similarity to neighboring dopamine neurons, medial VTA glutamate neurons may thus also contribute to aversive responses.

\section{Functional projections made by VTA glutamate neurons}

Medial and lateral VTA dopamine neurons also differ in their projections. Medial dopamine neurons project predominantly to medial PFC, medial olfactory tubercle, medial shell, and core of the NAc, whereas lateral dopamine neurons project to lateral parts of the ventral striatum and olfactory tubercle
(Fields et al., 2007; Ikemoto, 2007). VTA glutamate neurons have received less attention, but recent tract tracing studies have shown that in addition to making local synaptic connections with both dopamine and GABA neurons in the VTA (Dobi et al., 2010), they project to both NAc and PFC, at least in rat (Yamaguchi et al., 2011; Gorelova et al., 2012). However, the VTA projection to the NAc includes a higher proportion of dopaminergic inputs (including those that coexpress VGLUT2), and the PFC projection includes a higher proportion of glutamate inputs (Yamaguchi et al., 2011; Gorelova et al., 2012).

To visualize all of the projections made by VTA glutamate neurons, we used mice that express Cre recombinase in VGLUT2 ${ }^{+}$neurons and stereotactically injected a virus encoding a conditional allele of ChR2-mCherry that requires activation by Cre (Tsai et al., 2009). Since the high amplification that results and the widespread expression of VGLUT2 in surrounding regions (such as the red nucleus and interpeduncular and mammillary nuclei) require precise injection into the medial VTA, we analyzed only three of twenty-six animals in detail. Variability in the number of neurons transduced by virus and the expression of the reporter has also made quantitation difficult. However, we found both $\mathrm{TH}^{+}$and $\mathrm{TH}^{-}$mCherry $^{+}$neurons in the VTA- and 
A

\section{Nucleus Accumbens}

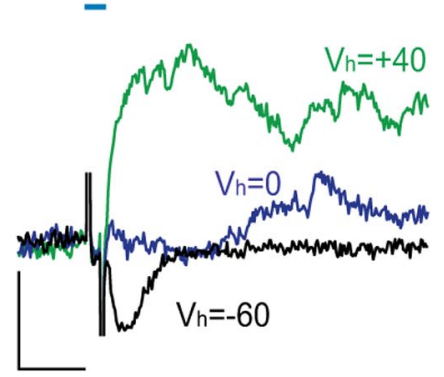

D
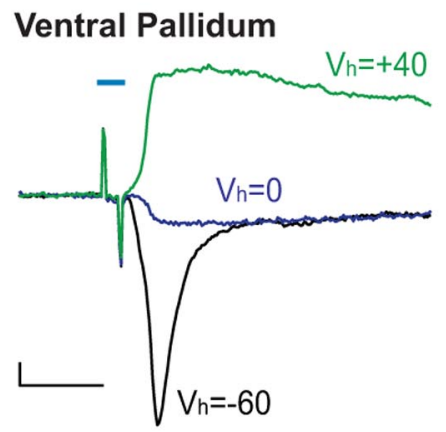

B

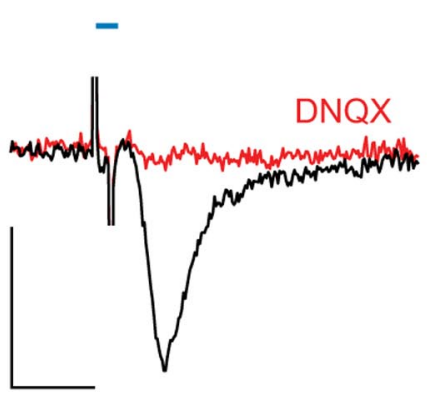

E

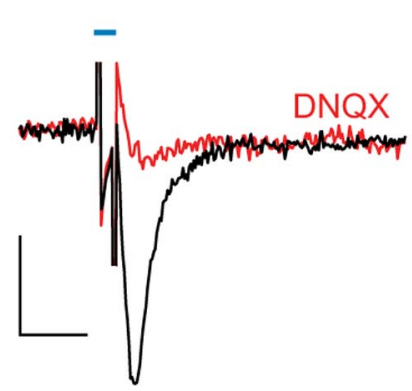

C

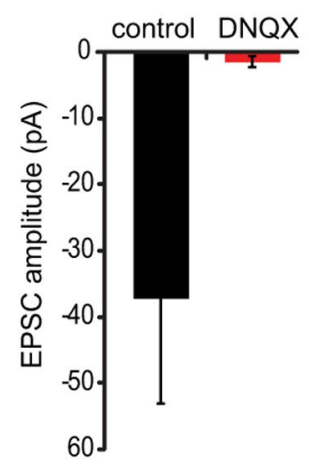

$\mathbf{F}$

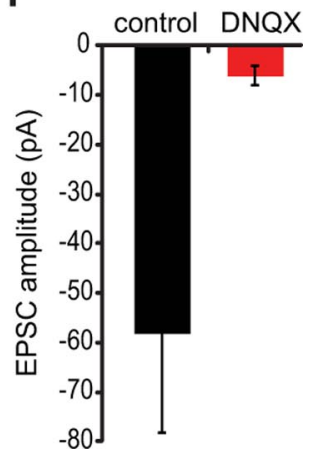

Figure 6. VTA projections form functional synapses in both the nucleus accumbens and ventral pallidum. A, More than 3 weeks after stereotactic injection of AAV-EF1 $\alpha$-DI0-ChR2$\mathrm{mCherry}$ into the medial VTA, striatal slices show light-evoked currents in NAc neurons. Representative traces from NAc neurons held at the potentials indicated show both AMPARmediated (black trace) and NMDAR-mediated (green trace) excitatory currents. B, C, The AMPAR antagonist DNQX (red trace) blocks the AMPAR-mediated currents observed at $-60 \mathrm{mV}$ $(5.9 \% \pm 3.9 \%$ residual current following DNQX, $p<0.001$ by within-cell paired $t$ test, $n=5) \boldsymbol{D}-\boldsymbol{F}$, Neurons in the VP exhibit similar light-evoked synaptic currents $(\boldsymbol{D})$ and those mediated by AMPAR are also DNQX-sensitive $(\boldsymbol{E}, \boldsymbol{F})(9.9 \% \pm 3.9 \%$ residual current following DNQX, $p<0.001$ by within-cell paired $t$ test, $n=10)$. Black scale bars, $20 \mathrm{pA}, 10 \mathrm{~ms}$; blue bar represents the 2 ms blue light pulse.

mCherry ${ }^{+}$(both $\mathrm{TH}^{+}$and $\mathrm{TH}^{-}$) fibers in the NAc, PFC, and amygdala - as previously shown by tract tracing in the rat (Yamaguchi et al., 2011; Gorelova et al., 2012). In addition, the robust labeling with mCherry enabled us to detect a higher density of projections in the cone and vertex of the NAc medial shell than in more lateral regions of the ventral striatum. Indeed, the mCherry ${ }^{+}$projections appear concentrated in regions of the striatum receiving less $\mathrm{TH}^{+}$input, suggesting topographic differences between the two pathways within the ventral striatum. We have also taken advantage of the ChR2 fusion to evoke transmitter release from the mCherry ${ }^{+}$terminals and observed fast glutamatergic responses in the NAc, demonstrating the excitatory nature of this synaptic connection. The glutamatergic projection to the PFC was scant relative to previous observations in the rat (Yamaguchi et al., 2011; Gorelova et al., 2012), but the dopaminergic projection to the cortex also appears sparse in mice.

In addition to brain regions known to receive dopaminergic projections, we find that VTA glutamate neurons project to two regions not widely recognized to receive dopaminergic input from the VTA. Previous work has described a nondopaminergic projection from VTA to LHb (Swanson, 1982), and our results indicate that these neurons express VGLUT2. LHb neurons fire in response to outcomes that are worse than predicted (Matsumoto and Hikosaka, 2007), indirectly inhibiting VTA dopamine neurons through activation of inhibitory neurons in the rostromedial tegmental nucleus (Hong et al., 2011). Thus, the excitatory input to LHb from medial VTA glutamate neurons may serve indirectly to inhibit VTA dopamine neurons. Interestingly, a subset of VTA neurons that respond to aversive stimuli does not appear to be dopaminergic (Ungless et al., 2004; Brischoux et al., 2009), and these may in fact include some of the VGLUT2 ${ }^{+}$ population. Consistent with this possibility, the AMPA/NMDA ratio is altered in PFC-projecting VTA neurons responsive to aversive stimuli (Lammel et al., 2011), and this projection is primarily glutamatergic (Yamaguchi et al., 2011; Gorelova et al., 2012).

The present results also show a major projection from VTA glutamate-only neurons to the VP. In the rostral VP, mCherry ${ }^{+}$fibers fill in the gaps between $\mathrm{TH}^{+}$projections to the ventral NAc and dorsal olfactory tubercle, again supporting topographic segregation of the two pathways. To assess the function of synapses formed by VTA glutamate neurons, we used optical stimulation to evoke transmitter release and recorded substantial AMPAR- and NMDAR-mediated currents in postsynaptic neurons of the VP. It is important to note that more virus was injected into the VTA to achieve the higher levels of ChR2 expression required for photostimulation, and ChR2 expression was thus observed in brain regions neighboring the VTA, such as the red nucleus and mammillary bodies (data not shown). However, these nuclei are not known to project to the VP or NAc and are therefore unlikely to be responsible for the photocurrents. The role of glutamate released from VTA terminals in the VP remains unclear; however, glutamate signaling at this site may contribute to rewards. Indeed, selective VP lesions abolish 'liking," "want- 
ing," and "learning" of food rewards, and excitation or disinhibition of the VP strongly promotes food wanting (Smith and Berridge, 2005; Shimura et al., 2006; Smith et al., 2009). Interestingly, we have also observed GABA responses evoked by stimulation of VGLUT2 ${ }^{+}$projections to both the NAc and the VP. Although the source of GABA released remains unclear, the short synaptic delay observed in the VP raises the possibility of GABA release by VGLUT2 ${ }^{+}$VTA neurons, with the longer delay observed in NAc more consistent with polysynaptic transmission.

In conclusion, we have demonstrated the presence of a glutamatergic population in the medial VTA that resembles medial dopamine neurons in terms of electrophysiological properties but differs from more lateral dopamine cells. This novel population projects to NAc, PFC, and amygdala in parallel with dopamine neurons, but also makes divergent projections to LHb and VP, where they establish functional excitatory synapses. Their projection to the LHb in particular suggests a role in responsiveness to aversive stimuli as well as reinforcement learning.

\section{References}

Bäckman CM, Malik N, Zhang Y, Shan L, Grinberg A, Hoffer BJ, Westphal H, Tomac AC (2006) Characterization of a mouse strain expressing Cre recombinase from the $3^{\prime}$ untranslated region of the dopamine transporter locus. Genesis 44:383-390. CrossRef Medline

Borgius L, Restrepo CE, Leao RN, Saleh N, Kiehn O (2010) A transgenic mouse line for molecular genetic analysis of excitatory glutamatergic neurons. Mol Cell Neurosci 45:245-257. CrossRef Medline

Brischoux F, Chakraborty S, Brierley DI, Ungless MA (2009) Phasic excitation of dopamine neurons in ventral VTA by noxious stimuli. Proc Natl Acad Sci U S A 106:4894-4899. CrossRef Medline

Cameron DL, Wessendorf MW, Williams JT (1997) A subset of ventral tegmental area neurons is inhibited by dopamine, 5 -hydroxytryptamine and opioids. Neuroscience 77:155-166. CrossRef Medline

Chuhma N, Zhang H, Masson J, Zhuang X, Sulzer D, Hen R, Rayport S (2004) Dopamine neurons mediate a fast excitatory signal via their glutamatergic synapses. J Neurosci 24:972-981. CrossRef Medline

Dobi A, Margolis EB, Wang HL, Harvey BK, Morales M (2010) Glutamatergic and nonglutamatergic neurons of the ventral tegmental area establish local synaptic contacts with dopaminergic and nondopaminergic neurons. J Neurosci 30:218-229. CrossRef Medline

El Mestikawy S, Wallén-Mackenzie A, Fortin GM, Descarries L, Trudeau LE (2011) From glutamate co-release to vesicular synergy: vesicular glutamate transporters. Nat Rev Neurosci 12:204-216. CrossRef Medline

Fields HL, Hjelmstad GO, Margolis EB, Nicola SM (2007) Ventral tegmental area neurons in learned appetitive behavior and positive reinforcement. Annu Rev Neurosci 30:289-316. CrossRef Medline

Fremeau RT Jr, Voglmaier S, Seal RP, Edwards RH (2004) VGLUTs define subsets of excitatory neurons and suggest novel roles for glutamate. Trends Neurosci 27:98-103. CrossRef Medline

Gong S, Zheng C, Doughty ML, Losos K, Didkovsky N, Schambra UB, Nowak NJ, Joyner A, Leblanc G, Hatten ME, Heintz N (2003) A gene expression atlas of the central nervous system based on bacterial artificial chromosomes. Nature 425:917-925. CrossRef Medline

Gorelova N, Mulholland PJ, Chandler LJ, Seamans JK (2012) The glutamatergic component of the mesocortical pathway emanating from different subregions of the ventral midbrain. Cereb Cortex 22:327-336. CrossRef Medline

Hnasko TS, Edwards RH (2012) Neurotransmitter corelease: mechanism and physiological role. Annu Rev Physiol 74:225-243. CrossRef Medline

Hnasko TS, Chuhma N, Zhang H, Goh GY, Sulzer D, Palmiter RD, Rayport S, Edwards RH (2010) Vesicular glutamate transport promotes dopamine storage and glutamate corelease in vivo. Neuron 65:643-656. CrossRef Medline

Hong S, Jhou TC, Smith M, Saleem KS, Hikosaka O (2011) Negative reward signals from the lateral habenula to dopamine neurons are mediated by rostromedial tegmental nucleus in primates. J Neurosci 31:11457-11471. CrossRef Medline
Hornykiewicz O (1962) [Dopamine (3-hydroxytyramine) in the central nervous system and its relation to the Parkinson syndrome in man]. Dtsch Med Wochenschr 87:1807-1810. CrossRef Medline

Ikemoto S (2007) Dopamine reward circuitry: two projection systems from the ventral midbrain to the nucleus accumbens-olfactory tubercle complex. Brain Res Rev 56:27-78. CrossRef Medline

Johnson SW, North RA (1992a) Opioids excite dopamine neurons by hyperpolarization of local interneurons. J Neurosci 12:483-488. Medline

Johnson SW, North RA (1992b) Two types of neurone in the rat ventral tegmental area and their synaptic inputs. J Physiol 450:455-468. Medline

Kawano M, Kawasaki A, Sakata-Haga H, Fukui Y, Kawano H, Nogami H, Hisano S (2006) Particular subpopulations of midbrain and hypothalamic dopamine neurons express vesicular glutamate transporter 2 in the rat brain. J Comp Neurol 498:581-592. CrossRef Medline

Lacey MG, Mercuri NB, North RA (1989) Two cell types in rat substantia nigra zona compacta distinguished by membrane properties and the actions of dopamine and opioids. J Neurosci 9:1233-1241. Medline

Lammel S, Hetzel A, Häckel O, Jones I, Liss B, Roeper J (2008) Unique properties of mesoprefrontal neurons within a dual mesocorticolimbic dopamine system. Neuron 57:760-773. CrossRef Medline

Lammel S, Ion DI, Roeper J, Malenka RC (2011) Projection-specific modulation of dopamine neuron synapses by aversive and rewarding stimuli. Neuron 70:855-862. CrossRef Medline

Lavin A, Nogueira L, Lapish CC, Wightman RM, Phillips PE, Seamans JK (2005) Mesocortical dopamine neurons operate in distinct temporal domains using multimodal signaling. J Neurosci 25:5013-5023. CrossRef Medline

Luo AH, Georges FE, Aston-Jones GS (2008) Novel neurons in ventral tegmental area fire selectively during the active phase of the diurnal cycle. Eur J Neurosci 27:408-422. CrossRef Medline

Luo Y, Good CH, Diaz-Ruiz O, Zhang Y, Hoffman AF, Shan L, Kuang SY, Malik N, Chefer VI, Tomac AC, Lupica CR, Bäckman CM (2010) NMDA receptors on non-dopaminergic neurons in the VTA support cocaine sensitization. PLoS One 5:e12141. CrossRef Medline

Madisen L, Zwingman TA, Sunkin SM, Oh SW, Zariwala HA, Gu H, Ng LL, Palmiter RD, Hawrylycz MJ, Jones AR, Lein ES, Zeng H (2010) A robust and high-throughput Cre reporting and characterization system for the whole mouse brain. Nat Neurosci 13:133-140. CrossRef Medline

Margolis EB, Lock H, Hjelmstad GO, Fields HL (2006) The ventral tegmental area revisited: is there an electrophysiological marker for dopaminergic neurons? J Physiol 577:907-924. CrossRef Medline

Margolis EB, Mitchell JM, Ishikawa J, Hjelmstad GO, Fields HL (2008) Midbrain dopamine neurons: projection target determines action potential duration and dopamine $\mathrm{D}(2)$ receptor inhibition. J Neurosci 28:89088913. CrossRef Medline

Matsumoto M, Hikosaka O (2007) Lateral habenula as a source of negative reward signals in dopamine neurons. Nature 447:1111-1115. CrossRef Medline

Mendez JA, Bourque MJ, Dal Bo G, Bourdeau ML, Danik M, Williams S, Lacaille JC, Trudeau LE (2008) Developmental and target-dependent regulation of vesicular glutamate transporter expression by dopamine neurons. J Neurosci 28:6309-6318. CrossRef Medline

Nair-Roberts RG, Chatelain-Badie SD, Benson E, White-Cooper H, Bolam JP, Ungless MA (2008) Stereological estimates of dopaminergic, GABAergic and glutamatergic neurons in the ventral tegmental area, substantia nigra and retrorubral field in the rat. Neuroscience 152:10241031. CrossRef Medline

Olson VG, Nestler EJ (2007) Topographical organization of GABAergic neurons within the ventral tegmental area of the rat. Synapse 61:87-95. CrossRef Medline

Omelchenko N, Sesack SR (2009) Ultrastructural analysis of local collaterals of rat ventral tegmental area neurons: GABA phenotype and synapses onto dopamine and GABA cells. Synapse 63:895-906. CrossRef Medline

Pape HC (1996) Queer current and pacemaker: the hyperpolarizationactivated cation current in neurons. Annu Rev Physiol 58:299-327. CrossRef Medline

Robinson RB, Siegelbaum SA (2003) Hyperpolarization-activated cation currents: from molecules to physiological function. Annu Rev Physiol 65:453-480. CrossRef Medline

Shimura T, Imaoka H, Yamamoto T (2006) Neurochemical modulation of ingestive behavior in the ventral pallidum. Eur J Neurosci 23:15961604. CrossRef Medline 
Smith KS, Berridge KC (2005) The ventral pallidum and hedonic reward: neurochemical maps of sucrose "liking" and food intake. J Neurosci 25: 8637-8649. CrossRef Medline

Smith KS, Tindell AJ, Aldridge JW, Berridge KC (2009) Ventral pallidum roles in reward and motivation. Behav Brain Res 196:155-167. CrossRef Medline

Stuber GD, Hnasko TS, Britt JP, Edwards RH, Bonci A (2010) Dopaminergic terminals in the nucleus accumbens but not the dorsal striatum corelease glutamate. J Neurosci 30:8229-8233. CrossRef Medline

Swanson LW (1982) The projections of the ventral tegmental area and adjacent regions: a combined fluorescent retrograde tracer and immunofluorescence study in the rat. Brain Res Bull 9:321-353. CrossRef Medline

Takamori S (2006) VGLUTs: 'exciting' times for glutamatergic research? Neurosci Res 55:343-351. CrossRef Medline

Tecuapetla F, Patel JC, Xenias H, English D, Tadros I, Shah F, Berlin J, Deisseroth K, Rice ME, Tepper JM, Koos T (2010) Glutamatergic signaling by mesolimbic dopamine neurons in the nucleus accumbens. J Neurosci 30:7105-7110. CrossRef Medline

Tsai HC, Zhang F, Adamantidis A, Stuber GD, Bonci A, de Lecea L, Deisseroth $\mathrm{K}$ (2009) Phasic firing in dopaminergic neurons is sufficient for behavioral conditioning. Science 324:1080-1084. CrossRef Medline

Ungless MA, Magill PJ, Bolam JP (2004) Uniform inhibition of dopamine neurons in the ventral tegmental area by aversive stimuli. Science 303 : 2040-2042. CrossRef Medline

Yamaguchi T, Sheen W, Morales M (2007) Glutamatergic neurons are present in the rat ventral tegmental area. Eur J Neurosci 25:106-118. CrossRef Medline

Yamaguchi T, Wang HL, Li X, Ng TH, Morales M (2011) Mesocorticolimbic glutamatergic pathway. J Neurosci 31:8476-8490. CrossRef Medline

Zhang TA, Placzek AN, Dani JA (2010) In vitro identification and electrophysiological characterization of dopamine neurons in the ventral tegmental area. Neuropharmacology 59:431-436. CrossRef Medline 